\title{
Measurement of Perceived Parental Success Standards in Sport and Relations with Athletes' Self-Esteem, Performance Anxiety, and Achievement Goal Orientation: Comparing Parental and Coach Influences
}

\author{
Frank J. Schwebel, Ronald E. Smith, and Frank L. Smoll \\ Department of Psychology, University of Washington, Seattle, WA 98195-1525, USA \\ Correspondence should be addressed to Frank J. Schwebel; fschwebe@uw.edu \\ Received 30 July 2015; Revised 15 January 2016; Accepted 20 January 2016 \\ Academic Editor: Elena Nicoladis
}

Copyright (C) 2016 Frank J. Schwebel et al. This is an open access article distributed under the Creative Commons Attribution License, which permits unrestricted use, distribution, and reproduction in any medium, provided the original work is properly cited.

\begin{abstract}
The Perceived Parent Success Standards Scale (PPSSS), adapted from the Perception of Success Questionnaire constructed by Roberts et al. (1998) to measure athletes' achievement goal orientation, provides a measure of athletes' perceptions of masteryand ego-oriented parental success criteria, a central component of parental motivational climate. This study focused on 543 young athletes (ages 9-16) on 82 teams in recreational basketball leagues. The PPSSS exhibited strong factorial validity, construct validity, and orthogonality between ego and mastery factors that allow for different combinations of these factors to be tested. We also compared the impact of the motivational climates created by coaches and success standards conveyed by parents on postseason athlete outcome measures of anxiety, self-esteem, and achievement goal orientation. Correlational and multilevel regression analyses revealed that both coach and parent variables were significantly related to the athlete variables. However, mediational analyses indicated that parental success standards mediated relations between coach-initiated climate and all of the outcome variables, reflecting the power of parental socialization processes. We discuss potential reasons for the greater parental influence shown in this and a previous study, and we suggest directions for further research as well as possible interventions that can help both coaches and parents create a more positive athletic environment for young athletes.
\end{abstract}

\section{Introduction}

It is estimated that more than 45 million children and adolescents participate in team sports in the United States each year [1]. Millions more likely participate in individual sports such as swimming and golf. This represents more than half of all people in the 6-18 age range [2]. Youth sports provide an opportunity for participants to develop important social skills, values, attitudes, and motivational styles. Achievement goal orientation, as described in Achievement Goal Theory (AGT), provides a framework for understanding how individuals interpret and respond to achievement activity [3-6]. AGT posits that by understanding the function and meaning of a person's success standards and goal directed actions one can understand his or her motivation.
Within AGT, there are two distinct achievement goal orientations-ego and mastery-that are used to define success and measure competency. In a mastery achievement goal orientation, success is self-referenced and characterized by achieving personal goals, task mastery, and exhibiting maximum effort and dedication [7]. Also, mistakes are not punished; rather they are treated as an opportunity for selfimprovement $[7,8]$. Because success is not evaluated relative to others, it is possible for young athletes with a mastery orientation to perceive themselves as having less talent or ability than others and still feel successful and competent $[3,4]$. In contrast, an ego achievement goal orientation measures success relative to others and is characterized by outperforming or outwitting others, or by performing similarly to others, but with equivalent or less effort $[7,9]$. 
Mistakes are considered unacceptable and they are punished. To have tried hard and "failed" with such an orientation would make the athlete feel particularly incompetent [4]. Furthermore, noticing personal improvement or knowing that one gave maximum effort would not elicit a sense of success or be viewed as a demonstration of competence if egooriented success criteria have been internalized.

Mastery orientation has been studied and related to high levels of achievement and positive motivational outcomes, such as the belief that effort is a cause of success, the use of problem-solving and adaptive learning strategies, the exertion of consistent effort, and persistence in the face of adversity $[7,9,10]$. Ego orientation has been correlated with a number of less desirable outcomes, such as inconsistent effort, increased levels of performance anxiety, reduced persistence and increased rate of withdrawal in the face of failure, and a willingness to use deception and to cheat in order to win $[7,9,11-13]$. When comparing mastery and ego achievement goal orientations, individuals with mastery orientations tend to display increased enjoyment, intrinsic motivation and interest, and satisfaction $[7,9,14]$.

Just as there are individual achievement goal orientations that can be classified as either ego-involved or mastery based, there are also situational climates that could be similarly classified. Motivational climates are classically defined as the pattern of normative influences, evaluative standards, rewards and sanctions, interpersonal interactions, and values communicated within the achievement environment [15]. Both climates are influenced by the interaction of personal and situational factors [5, 8]. For example, key socializing agents in youth sports, namely, coaches and parents, can create a climate that is strongly influenced by what they reinforce, as well as the attitudes and values they transmit through their words and actions. It is important to distinguish between these climates because they have been found to profoundly and differentially affect a wide variety of variables, such as an individual's self-esteem, sense of competency, quality of experience, and level of performance anxiety [4, $8,16]$. In a mastery climate, socializing agents define success in terms of self-improvement, task mastery, and exhibiting maximum effort and dedication [7]. They also create a setting in which they reinforce effort, cooperation, learning, and improvement [9]. In such a setting, athletes display maximal effort, persist in the face of setbacks, are proud of personal improvement, and utilize other adaptive achievement strategies [7]. In an ego climate, socializing agents define success in terms of social comparisons and create a setting in which they provide differential reinforcement between team members $[7,9]$. In this climate, coaches foster rivalry among team members, punish mistakes, and care more about winning than about effort expended, enjoyment, and personal improvement [7, 9].

Coaches are a major socializing influence in sports [7$9,17]$. Though their direct influence is typically limited to the athletic environment, they may spend long hours with youth, creating a climate that has been shown to affect athlete motivation and quality of experience in sports [8]. There have been a number of studies investigating the influence of coaches on athlete motivation [18-20]. The motivational climates created by coaches have been found to predict athlete emotional, cognitive, and behavioral outcomes (including sport performance anxiety) [18]. Sport performance anxiety is defined as a predisposition to experience cognitive anxiety (e.g., negative thoughts) and/or somatic anxiety (e.g., muscle tension and other forms of physiological arousal) in a competitive sport situation [21-23]. Scanlan and Passer [2426] found that coach motivational climate had a significant impact upon sport performance anxiety and self-esteem. Specifically, they found that mastery climates led to decreased anxiety and increased self-esteem, whereas ego climates had the opposite effects. Lewthwaite and Scanlan [21] found similar effects. Sports present evaluative situations (e.g., a basketball game) that can lead to cognitive and physiological arousal $[27,28]$. Sport performance anxiety can lead to a variety of negative consequences, such as lowered self-esteem, greater disappointment after a poor performance, increased avoidance behavior, and increased dropout rates [21]. As such, reduction in anxiety is associated with improved sport experiences.

It is generally held that parents are typically the main socializing influence on their children and have an indelible influence on their overall psychosocial development [29]. Thus, as one might expect, the motivational climate created by parents, driven by their own achievement goal orientation, also has a major influence upon young athletes' achievement goal orientation [4]. One focus of study has been on the effect of parental motivational climate upon sport performance anxiety. Researchers have found that a parental ego climate is related to high performance anxiety [22]. Conversely, Ames [10] found that a high mastery climate is linked to lower performance anxiety. Likewise, Lewthwaite and Scanlan [21] found that mastery climates led to decreased sport performance anxiety and increased self-esteem. Ego climates had the opposite effects.

Another area of study on the effects of parental motivational climates has focused on young athletes' self-esteem. A number of studies suggest that parental mastery motivational climates help protect or increase athlete self-esteem while ego motivational climates display the opposite effects [22, 30, 31]. These findings exhibit the same directional relationship with regard to self-esteem as those found on the impact of coach motivational climates on young athletes $[5,32,33]$.

The influence of parents is not limited to the domain of sports. Nonsport studies have also investigated the impact of youth perception of parental pressures, goals, motivations, and support on outcomes such as maladjustment, career aspirations, and adolescent well-being [34-37]. Within an affluent population, parental perfectionism (a trait associated with an ego orientation) was used as a measure of perceived parental pressure among adolescents [35]. The findings indicated that as adolescents' perception of parental pressure increased so too did adjustment problems. Congruence between parental and adolescent career goals has been tested as a moderator between achievement goal orientation (mastery and ego) and career aspirations. Sawitri and Creed [36] found that perceived goal congruence moderated the effect of achievement goal orientation on career aspirations of adolescents. A mastery orientation was related to higher 
career aspirations than was ego orientation when congruence was higher. Another study investigated perceived levels of parental support, measured by levels (high, moderate, and low) of parental involvement and warmth, and the amount of encouraged autonomy. The results indicated that higher levels of perceived parental support were related to higher levels of adolescent well-being and autonomy [34]. Thus, in a variety of settings, the motivational climate created by parents has a profound influence on a variety of outcome variables in children.

Because motivational climates are created by the patterns of behavior and reinforcement of key socializing agents, the effects of the actions are perceived and interpreted by children. The inferred values and beliefs of socializing agents are of particular significance, and, according to AGT, they constitute a core component of the motivational climate. For example, if an athlete perceives their coach as fostering intrateam rivalry, comparing athletes with one another, and rewarding individual achievement rather than personal improvement, they would likely conclude that the coach's major conception of success involved outdoing others. In support of this proposition, White [38] found that anxiety was related to youth perception of what they think their parents value or deem important and the subsequent achievement pressures they experienced. Specifically, youth who perceived their parents as having high sport outcome expectations for them were more likely to report high levels of anxiety prior to competition.

Although a variety of measures of both achievement goal orientations and motivational climates have been developed within the context of AGT, there exists no direct measure of perceived parental success standards. In this study, we report on the development of such a measure that was derived from a well-established measure of athletes' mastery and ego achievement goal orientations, the Perception of Success Questionnaire (POSQ) [39]. Our goal was to develop a measure that reflects the orthogonality between ego and mastery goal orientations posited by AGT and exhibited by several measures of athlete goal orientations [39, 40]. Our adaptation of the POSQ gave rise to the Perceived Parent Success Standards Scale (PPSSS). We believed that such a measure would provide a more precise assessment of relations between perceived parental success criteria and motivational and personality variables in young athletes.

We focused our study on a preadolescent athlete population. Preadolescence is an important formative period for children's psychosocial development in sport, being characterized by some of the most rapid physical and mental changes individuals will encounter throughout their lifetime [41]. Specifically, starting around age 9, children begin to understand the concept of competitive ability, which is a foundation for the formation of their own motivational style that gradually emerges during the period of time between late childhood and early adolescence [6]. The PPSSS was designed for and developed using this age group.

The PPSSS provides an alternative to the Parent-Initiated Motivational Climate Questionnaire-2 (PIMCQ-2) [38], the measure that is most widely employed to assess parental motivational climate. The PIMCQ-2 assesses more facets of motivational climate than does the PPSSS, as it measures the facets of learning orientation, worry-promotion, and success without effort. The scale was developed for use with an older cohort than this study's sample, and it has a somewhat higher reading level compared to other child-specific measures such as the POSQ or the Achievement Goal Scale for Youth Sports (AGSYS) [40]. The PIMCQ-2 also has exhibited lower levels of internal consistency for our target population age range than it has for slightly older adolescents [42]. Moreover, ego and mastery factors are moderately to highly negatively correlated in the PIMCQ-2, which is at variance with the orthogonality found in the POSQ [39] and in the AGSYS used in this study. Finally, questions exist about the factorial validity of the PIMCQ-2. In a recent study that attempted to validate the three-factor PIMCQ-2 for use in Spain [43], confirmatory factor analysis revealed a poor factor fit to the underlying model. The authors suggested that further research on the PIMCQ-2 structure and factor fit is merited. In another study using a preadolescent sample of athletes, the three-factor structure established in an older sample was not supported and a two-factor solution was more reflective of the discriminations made among parental behaviors at this age level [8]. The fact that the POSQ has exhibited strong psychometric properties and an orthogonal ego and mastery factor structure [12, 39] suggested that a parental standards adaptation might also exhibit the hypothesized factor structure.

This study had two major goals. The first was to assess the psychometric properties of the new scale and to assess its construct validity as reflected in its relationship to other athlete variables. On the basis of AGT as well as previous research results, we expected a similar pattern of relationships between the PPSSS and the athlete criterion variables to that exhibited in earlier research on coach and parent motivational climate. Specifically, we predicted that high perceived parent mastery standards and high coach mastery climate scores would be positively associated with young athletes' self-esteem levels and mastery achievement goal orientation and negatively associated with anxiety and ego achievement goal orientation. We also expected that high parent ego success standards and high coach ego climate scores would be positively associated with athletes' anxiety and ego achievement goal orientation and negatively associated with athletes' self-esteem and mastery achievement goal orientation. These hypothesized relationships with athletes' achievement goals orientations, self-esteem, and anxiety address not only theoretical expectations, but also the construct validity of the PPSSS.

A second goal of this study was a comparison of the relative impact of perceived parental standards with that of the coach-initiated motivational climate. Do parental or coach factors have a stronger impact on young athletes? This question, though subject to speculation, has received surprisingly little empirical attention. To date, only one study, by O'Rourke et al. [8], has compared the relative influence of parents' and coaches' motivational climate on young athletes. That study involved a sample of swimmers in an Olympic development program with highly involved and committed parents. O'Rourke et al. [8] hypothesized that, in such 
a setting, parent-initiated motivational climate would have a greater impact on athletes in the domains of performance trait anxiety, self-esteem, and autonomous motivation than coach motivational climate. Using a hierarchical regression approach in which coach motivational climate was entered before parent climate, O'Rourke et al. found that both coach and parent climates were significantly predictive of anxiety, self-esteem, and autonomy in the predicted directions, with parent climate having the larger beta value in each case. However, when the order of entry was reversed, with parent climate entered first, controlling for parent climate eliminated the significant relations for coach climate in all cases. O'Rourke et al. concluded that the effects of parent climate exceed that of coach climate. However, they pointed out that their results were derived from a sample having extremely high and direct parent involvement, and they questioned whether similar results would occur in a sport environment having less parental involvement and commitment. Our study was designed in part to add to the limited literature on the relative influence of coach and parent factors relating to motivational climate, this time within a recreational program having far less direct parental involvement.

Lastly, we used mediational analyses to assess if, given the long history of familial socialization experienced by athletes, perceived parental success standards might mediate the relationship between coach motivational climate and athlete outcome variables. On the basis of socialization theory, we expected that our results would be consistent with those found by O'Rourke et al. [8]. That is, we expected to find that perceived parental success standards would be strong enough to mediate, or override, athlete's response to motivational climates created by coaches.

\section{Method}

2.1. Participants. Six hundred and twelve basketball players (369 boys and 243 girls, $\mathrm{M}$ age $=11.76, \mathrm{SD}=1.56$, and age range $=9-16)$ on 82 teams from 5 recreational basketball leagues in the western United States participated in the study. Of the $65 \%$ who disclosed their ethnicity, $51.5 \%(n=315)$ were Caucasian, $4.0 \%(n=24)$ were Asian, and the remainder represented other or mixed ethnic group ancestry $(n=53)$. Athletes who were coached by their own parents $(n=69)$ were excluded in order to avoid any potential confounding of parent and coach roles, resulting in a final sample of 543 athletes on whom the results reported below are based. All 82 coaches were males. The median time that the athletes played for their current coach prior to the beginning of the season was 2 years. Over $90 \%$ of the athletes $(N=509)$ reported playing other sports in addition to basketball.

\subsection{Measures}

2.2.1. Perceived Parental Success Standards. Following institutional review board approval, athlete perception of parent achievement goal orientation was assessed using the PPSSS, an adaptation of the POSQ [39]. (We express our appreciation to Glyn Roberts for his suggestion on how to adapt the Perception of Success Questionnaire to assess perceived parental success criteria.) The latter measure has been used in much previous research to measure success criteria in athletes. We used its items to tap perceptions of the parents' standards of success, a key component of parental achievement goal orientation. The derived PPSSS items have a reading level suitable for young sport participants. In it, young athletes answer questions that focus on their parents' definition of success exhibited by their parents. Each of the 12 items is prompted from the stem, "When I play sports, it is most important TO MY PARENTS that..." and responses are made on a 4-point Likert scale ranging from 1 (strongly disagree) to 4 (strongly agree). The PPSSS has both ego ("I beat other people") and mastery ("I master something I couldn't do before") subscales. The complete scale is presented in the appendix.

\subsubsection{Athlete Validity Criterion Measures}

Achievement Goal Orientation. The AGSYS [40] is a selfassessment measure that was used to assess athletes' achievement goal orientation. The 12 -item measure has two subscales: ego ("to me, success means being better than others") and mastery ("my goal is to master the skills in my sport"). Responses are made on a Likert scale ranging from 1 (not at all true) to 5 (very true). The AGSYS has high factorial $(\mathrm{CFI}=0.95)$ and construct validity, and acceptable scale reliability (Cronbach's alpha $=0.92$ (mastery) and 0.95 (ego) with participants similar in age to our sample). As shown in Table 1 , alpha $=0.80$ for mastery orientation and 0.89 for ego orientation in the present sample.

Performance Trait Anxiety. The Sport Anxiety Scale-2 (SAS2) [23] was used to measure trait performance anxiety. Each of the 15 items is prompted with the stem "before or while I compete in sports..." and responses are made on a 4-point Likert scale ranging from 1 (not at all) to 4 (very much). The SAS-2 assesses three dimensions of anxiety: somatic anxiety ("my muscles feel shaky"), worry ("I worry that I will let others down"), and concentration disruption ("I lose focus on the game"). The SAS-2 has high factorial $(\mathrm{CFI}=0.96)$ and construct validity [21]. The total global anxiety score is calculated by summing the items from the three subscales and was used as the measure of anxiety in this study (alpha $=0.91$ for our age group) [8]. Alpha was 0.93 in the present sample.

Self-Esteem. The Washington Self-Description Questionnaire (WSDQ) [32] was used to measure self-reported levels of self-esteem. As suggested by the literature on self-esteem measures [45], rather than focusing on specific areas of competence, the WSDQ is a 14-item global measure with two subscales: one positive ("I feel proud of myself") and the other negative ("I'm usually so poor at things, I feel like giving up"). The latter items are meant to counter acquiescence response set. Responses are made on a Likert scale ranging from 1 (not like me) to 4 (very much like me) and the questions were written in language suitable for comprehension by young athletes. The negatively toned items are reverse-scored to and combined with the positive self-descriptive items to yield a total self-esteem score. Research on the WSDQ has found that it has high internal consistency ( 0.80 to 0.86$)$, good test-retest 
TABLE 1: Means, standard deviations, correlations, and alpha coefficients for coach, parent, and athlete variables.

\begin{tabular}{|c|c|c|c|c|c|c|c|c|c|c|c|}
\hline & 1 & 2 & 3 & 4 & 5 & 6 & 7 & 8 & Mean & SD & $\alpha$ \\
\hline (1) Coach MC & - & $-0.39^{* *}$ & $0.29^{* *}$ & $-0.15^{* *}$ & $0.35^{* *}$ & $-0.33^{* *}$ & $-0.19^{* *}$ & $0.40^{* *}$ & 25.49 & 3.90 & 0.90 \\
\hline (2) Coach EC & & - & $-0.11^{*}$ & $0.35^{* *}$ & $-0.23^{* *}$ & $0.26^{* *}$ & $0.49^{* *}$ & $-0.18^{* *}$ & 10.80 & 4.17 & 0.85 \\
\hline (3) PPMSS & & & - & $-0.11^{*}$ & $0.37^{* *}$ & $-0.29^{* *}$ & $-0.17^{* *}$ & $0.49^{* *}$ & 3.63 & 0.43 & 0.84 \\
\hline (4) PPESS & & & & - & $-0.18^{* *}$ & $0.26^{* *}$ & $0.61^{* *}$ & $-0.12^{*}$ & 2.02 & 0.68 & 0.86 \\
\hline (5) Self-esteem & & & & & - & $-0.51^{* *}$ & $-0.14^{* *}$ & $0.40^{* *}$ & 46.30 & 6.92 & 0.86 \\
\hline (6) Performance anxiety & & & & & & - & $0.26^{* *}$ & $-0.23^{* *}$ & 24.79 & 8.88 & 0.93 \\
\hline (7) Ego AGO & & & & & & & - & 0.03 & 2.36 & 1.07 & 0.89 \\
\hline (8) Mastery AGO & & & & & & & & - & 4.50 & 0.58 & 0.80 \\
\hline
\end{tabular}

${ }^{*} p<0.05,{ }^{* *} p<0.01$.

Coach MC: mastery climate.

Coach EC: ego climate.

PPMSS: perceived parent mastery success standards.

PPESS: perceived parent ego success standards.

AGO: achievement goal orientation.

reliability, and validity as an outcome variable [32,33]. In the present sample, alpha was 0.86 .

2.2.3. Coach-Initiated Motivational Climate. To compare relations between the PPSSS and the criterion variables with their relations to athletes' perceptions of the motivational climate created by the coach, we used the Motivational Climate Scale for Youth Sports (MCSYS) [15]. The MCSYS was developed with age-appropriate language to measure athletes' perceptions of the coach's definition of success. It is comprised of 16 items with two subscales: ego ("winning games was the most important thing for the $\mathrm{COACH}$ ") and mastery ("the $\mathrm{COACH}$ made players feel good when they improved a skill"). Responses were made using a Likert scale ranging from 1 (not at all true) to 5 (very true). Research has found the MCSYS to have good reliability, high factorial validity $(\mathrm{CFI}=0.97)$, and strong construct validity $[16]$.

2.3. Procedure. After receiving written parental consent and athlete assent, young athletes were gathered in group settings and completed the measures used in this study 2 to 3 weeks before the end of the season. The coach and parents were not present during data collection, and athletes were assured that their names would be removed from the questionnaires and were completely confidential. To assess test-retest reliability of the PPSSS, data were collected at the beginning and end of the season. No coach data were collected at the beginning of the season since many athletes did not yet know their coach. Our results are therefore based on postseason relationships among these predictor and outcome variables.

\section{Results}

3.1. Psychometric Properties of the PPSSS. Means, standard deviations, alphas, and correlations among the predictor and criterion variables are reported in Table 1 . The scales display high internal consistency. Correlations among measures are highly significant with directionality that is consistent with prior research findings, such as coach mastery and ego climate scores as well as parent mastery and ego standards scores being negatively correlated.
As shown in Table 1, the parental achievement standards scales exhibited high internal consistency, and a correlation of -0.11 between them supported the assumption of orthogonality. Aggregated across all teams, the product-moment correlations exhibited the theoretically predicted directional relations with the anxiety, self-esteem, and achievement goal orientation variables.

3.2. Factorial Validity of the PPSSS. As noted above, the PPSSS is an adaptation of the POSQ, used to assess goal orientation in athletes [39]. Because the adaptation was to serve as a new measure to assess perceived parental success standards, it was important to ensure that it has sound psychometric properties. Confirmatory factor analysis was then carried out to test the hypothesized two-factor structure of the PPSSS, using RStudio (Version 0.98.1062) and the lavaan package [46]. We began by testing a bipolar onefactor model and found Comparative Fit Index (CFI), TuckerLewis Index (TLI), and root-mean square error of estimate (RMSEA) values of $0.56,0.46$, and 0.19 , respectively, reflecting a very poor model fit. Next, we tested the hypothesized twofactor (ego and mastery) factor structure. The CFI, TLI, and RMSEA values were $0.95,0.94$, and 0.07 , respectively. Using guidelines suggested by Bollen, Fan et al., and Nunnally and Bernstein [47-49], the two-factor fit was deemed appropriate with indices exceeding 0.90 and RMSEA below 0.10. As shown in Figure 1, loadings for the ego factor were high, ranging from 0.57 to 0.85 , as were those for the mastery factor (0.54 to 0.73 ). Twelve-week test-retest reliability was 0.48 for mastery and 0.54 for the mastery scales. These analyses support the PPSSS as being a measure with independent ego and mastery dimensions, acceptable factorial validity, and satisfactory stability over a 12 -week interval.

3.3. Correlational Analysis. As seen in Table 1, perceived parent mastery success standards and coach mastery motivational climates were significantly and positively correlated at 0.29 , and the corresponding parent and coach ego orientation scores positively correlated at 0.35 . However, the relatively modest common variance indicated that athletes were discriminating between the achievement standards expressed by parent and coach. 


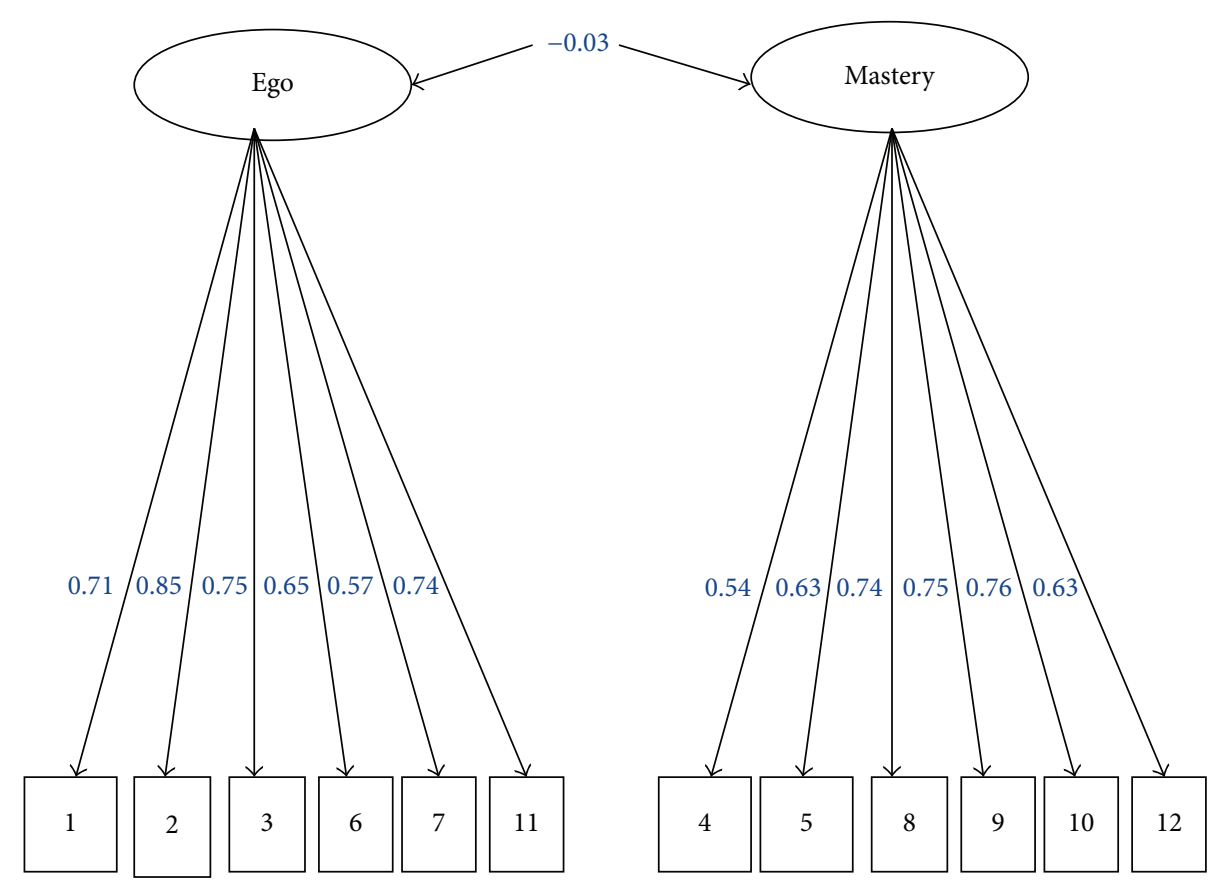

FIGURE 1: Confirmatory Factor Analysis Model and Item Factor Coefficients for the Perceived Parent Achievement Goal Orientation Scale.

As predicted, mastery scores for both parents and coaches were positively related to athlete self-esteem and athlete mastery achievement goal orientation and negatively correlated with anxiety and ego achievement goal orientation. Conversely, perceived parent and coach ego orientations were negatively correlated with postseason self-esteem and mastery achievement goal orientation and positively correlated with athlete anxiety and ego achievement goal orientation. Tests for the significance of differences between parent and coach correlations with the athlete measures were conducted. The only significant difference was a stronger relation between perceived parent ego standards and athlete ego achievement goal orientation $(r=0.61)$ than that found for coach ego climate $(r=0.45) z(438)=3.49, p<0.001$.

3.4. Multilevel (HLM) Regression Analysis. Using IBM SPSS Statistics-Version 21, Hierarchical Linear Modeling (HLM) was used to analyze the data, as it has a number of advantages over other methods for analyzing multilevel data. This was required because athletes are nested within teams (coaches), violating the assumption of within-team independence of athlete data and rendering basic regression models or analysis of variance tests inappropriate to analyze the data. HLM takes into account the nested nature of the data and allows for the examination of cross-level interactions [50]. Intraclass correlation coefficients (ICCs) were calculated for each of the four models using athlete anxiety, self-esteem, ego achievement goal orientation, and mastery achievement goal orientation as the dependent variables. The ICCs were $0.02,0.10,0.24$, and 0.14 , respectively, indicating a level of intrateam clustering that dictated a multilevel framework as the most appropriate procedure to analyze the data.
Overview of Models 1-4. Separate multilevel models were created for each of the four dependent variables. The models examined the effects of perceived parent achievement goal orientation and coach motivational climates and their interactions on the aforementioned outcomes. In order to test our hypothesis comparing the relative relations of parent success standards and coach motivational climate with the athlete variables, comparisons across models are required and are made possible by centering the scores within each team cluster. Creation of the models began with an empty or unconditional model, without any predictors. The first empty model included only a fixed intercept; the next one added a random intercept. The -2 restricted log likelihood ( $-2 \mathrm{RLL})$ score was used to determine whether to remove or retain the random intercept for each model. Then the empty models were used to calculate the ICC. The coach ego, coach mastery, parent ego, and parent mastery predictor variables were then entered together as fixed factors. After centering the predictor variables by cluster to reduce multicollinearity between the predictor variables and their interactions (i.e., product terms), Models 1-4 then had interactions entered and any significant interactions were probed. However, in the case of Model 4 (athlete mastery goal orientation), initial entry of the four predictor variables resulted in an error message indicating that a more parsimonious model was required in order to calculate reliable data. To calculate reliable results for this variable, predictors were entered one at a time rather than simultaneously and -2RLL scores and deviance tests (chi-squared tests, $\alpha=0.05$ ) were used after entering each predictor in order to measure model fit. For Model 4, the predictors that remained in the model were coach mastery and parent mastery. 
The results of the multilevel analyses are presented in Table 2. These analyses present the prediction coefficients and tests of their significance. An alpha level of 0.05 was adopted for all analyses.

Performance Anxiety. As shown in Model 1 of Table 2, three of the four predictors had statistically significant relations with athlete anxiety. Parent mastery standards and coach mastery climate produced significant negative coefficients $(p<0.001)$ while parent ego standard exhibited a significant positive coefficient $(p=0.002)$. As defined by magnitude of the coefficients, coach mastery climate was the strongest predictor, followed by parent mastery and parent ego standards, respectively. Coach ego climate was not statistically significant $(p>0.05)$. The interaction between parent and coach mastery orientations was statistically significant $(p<$ 0.05 ), indicating that a combination of high scores on both mastery measures was associated with low anxiety.

Self-Esteem. Three of the four predictors had a statistically significant relation with athlete self-esteem level in Model 2. As shown in Table 2, coach mastery climate and parent mastery standards yielded significant positive coefficients $(p<0.001)$, with parent standards yielding the larger coefficient. Coach ego climate had a significant negative coefficient $(p<0.01)$, but parent ego standards were not statistically significant $(p>0.05)$. None of the interactions were statistically significant.

Ego Achievement Goal Orientation. As shown in Table 2, only two of the four predictors had a statistically significant relation with athlete ego achievement goal orientation. Both coach ego climate and parent ego standards yielded statistically significant positive coefficients $(p<0.001)$, with parent ego achievement goal orientation exhibiting the stronger relation. Neither coach mastery climate nor parent mastery standards were statistically significant $(p>0.05)$, and none of the interactions were statistically significant.

Mastery Achievement Goal Orientation. As noted above, because of modeling constraints, Model 4 analysis of mastery goal orientation was able to utilize only the mastery coach and parent independent variables. As shown in Table 2, both coach mastery climate and parent mastery standards had statistically significant positive coefficients $(p<0.001)$, with parent mastery success standards yielding a stronger relation to athlete mastery achievement goal orientation. None of the interactions were statistically significant.

To summarize the results of the multilevel analysis as they bear on the relative influence of parents and coaches, we found that the largest statistically significant predictor in all of the models, with the exception of Model 1, was either parent ego or parent mastery success standards (see Table 2). In Model 1 we found coach mastery to be the most significant predictor of high performance anxiety.

3.5. Assessing Potential Mediational Relationships. Aside from their presumed influence on athletes' anxiety, self-esteem, and goal orientations, the child's longer and more pervasive exposure to parental standards may be expected to influence their response to the coach-initiated motivational climate, creating a preparedness to respond differentially to coach-communicated standards that are either consistent or inconsistent with parental standards. Therefore, another theoretically relevant question is the extent to which perceived parental standards of success mediate the relationships between coach motivational climate and youth outcomes. Since the focus of the question relates to sports, we chose not to include the self-esteem outcome as it is theoretically less related to sport participation than the other outcomes. We therefore focused on the sport-relevant variables of anxiety and achievement goal orientations in our mediational analyses. From a statistical perspective, mediation occurs if, in this case, controlling for differences in parental standards significantly reduces relationships between coach climate measures and the outcome variables.

Given the multilevel nature of the data, in each analysis, a 2-1-1 mediational model was computed with one level 2 variable, namely, the coach motivational climate predictor variable, and two level one variables, namely, the presumed mediator (perceived parental success standards) and the outcome variables (anxiety, mastery achievement goal orientation, and ego achievement goal orientation) as recommended by Bauer et al. [44]. We followed the procedure suggested by Zhang et al. [51] to assess mediation and used the stringent Aroian version of the Sobel test to assess significance (suggested procedure: (1) carry out an HLM analysis with the IV predicting the mediator to calculate $a$ (unstandardized regression coefficient for the association between IV and mediator) and $s_{a}$ (standard error of $a$ ), (2) run a second HLM analysis with the mediator predicting the DV while controlling for the IV to calculate $b$ (regression coefficient for the association between the mediator and DV, while controlling for the IV) and $s_{b}$ (standard error of $b$ ), and (3) use the Aroian test (defined in Table 3) to calculate a $z$ statistic and its associated significance level). As done in the HLM results described above, the group-mean-centered values of perceived parent scores were used and between and within group effects were tested separately. The reason for this is twofold: (1) to compare results across teams and (2) to avoid error of conflating within and between group effects as suggested by Zhang et al. [51]. An alpha level of 0.05 was adopted for all analyses. Separate analyses were done for each combination of coach, parent, and athlete variables. The results of the 12 mediational analyses are presented in Table 3 .

Anxiety. As shown in Table 3, significant $z$ scores in three of the four models revealed that parental success standards mediated the relationship between coach motivational climate and performance anxiety. Specifically, parent ego standards mediated the positive relationship between coach ego climate and performance anxiety. Parent ego standards also reduced the negative relationship between coach mastery climate and performance anxiety. Finally, parent mastery standards mediated the relationship between coach mastery climate and performance anxiety. Perceived parent mastery standards did not mediate the positive relationship between coach ego climate and performance anxiety. 


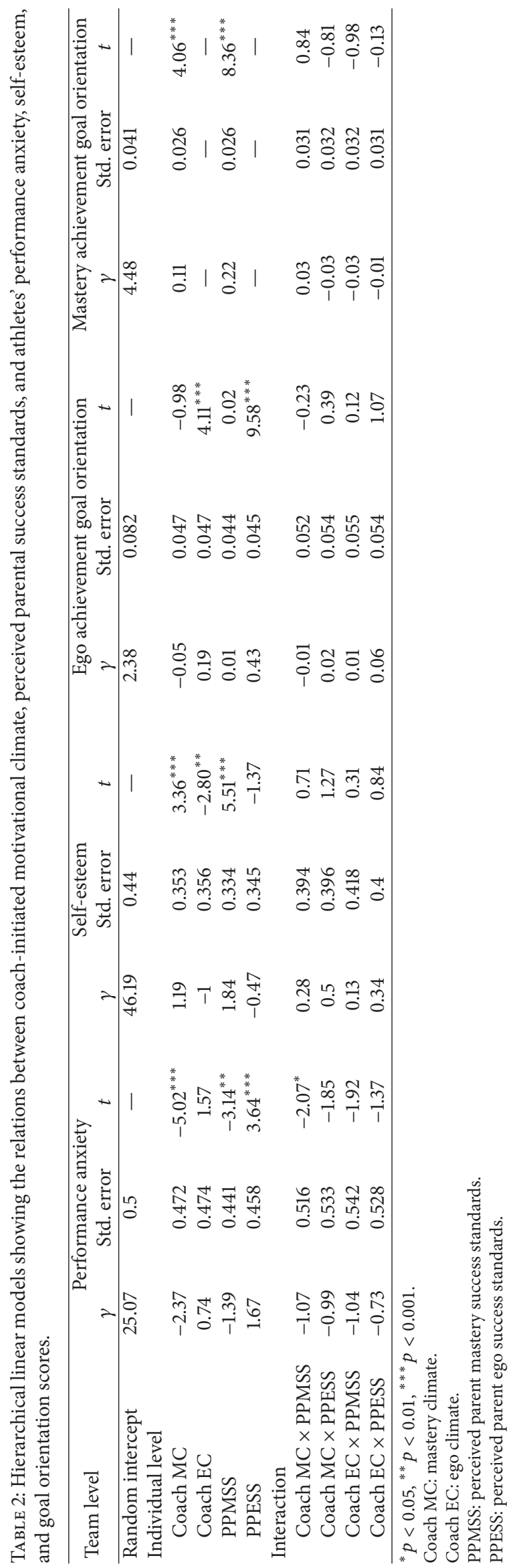


TABLE 3: Analyses assessing the mediational properties of parental success standards in relation to coach-initiated motivational climate as predictors of anxiety and achievement goal orientations.

\begin{tabular}{|c|c|c|c|}
\hline Athlete variable & Coach predictor variable & Parent mediator variable & $z$ \\
\hline \multirow{4}{*}{ Performance anxiety } & \multirow{2}{*}{ Coach mastery climate } & Perceived parent mastery standards & $-3.25^{* *}$ \\
\hline & & Perceived parent ego standards & $-2.47^{*}$ \\
\hline & \multirow{2}{*}{ Coach ego climate } & Perceived parent mastery standards & 0.18 \\
\hline & & Perceived parent ego standards & $3.35^{* * *}$ \\
\hline \multirow{4}{*}{ Mastery AGO } & \multirow{2}{*}{ Coach mastery climate } & Perceived parent mastery standards & $4.99^{* * *}$ \\
\hline & & Perceived parent ego standards & 0.88 \\
\hline & \multirow{2}{*}{ Coach ego climate } & Perceived parent mastery standards & -0.19 \\
\hline & & Perceived parent ego standards & -0.91 \\
\hline \multirow{4}{*}{ Ego AGO } & \multirow{2}{*}{ Coach mastery climate } & Perceived parent mastery standards & 0.05 \\
\hline & & Perceived parent ego standards & $-2.9^{* *}$ \\
\hline & \multirow{2}{*}{ Coach ego climate } & Perceived parent mastery standards & 0.1 \\
\hline & & Perceived parent ego standards & $5.77^{* * *}$ \\
\hline
\end{tabular}

Note. Significant $z$ scores indicate mediation by the parental success standards, reducing relations between the coach climate scores and the athlete criterion variables.

Aroian test equation [44]: $z=a * b / \sqrt{b^{2} * s_{a}^{2}+a^{2} * s_{b}^{2}+s_{a}^{2} * s_{b}^{2}}$.

$a$ : unstandardized regression coefficient for the association between the IV and the mediator.

$s_{a}:$ standard error of $a$.

$b$ : regression coefficient for the association between the mediator and the DV, when controlling for the IV.

$s_{b}$ : standard error of $b$.

${ }^{*} p<0.05,{ }^{* *} p<0.01$, and ${ }^{* * *} p<0.001$.

AGO: achievement goal orientation.

Mastery Achievement Goal Orientation. Only one of the four models revealed mediation of the relationships between coach motivational climate and athletes' mastery achievement goal orientations. As shown in Table 3, perceived parent mastery standards mediated the relationship between coach mastery climate and youth mastery achievement goal orientation, indicating that the positive relationship between the coach mastery climate and a mastery goal orientation could be largely accounted for by the impact of parental success standards. Perceived parent ego standards did not mediate the relationship between coach ego mastery climate and youth mastery achievement goal orientation, and parent mastery standards did not mediate the relationship between coach ego climate and youth mastery achievement goal orientation.

Ego Achievement Goal Orientation. As shown in Table 3, in two of the four models, parental standards mediated the relationship between coach motivational climate and youth ego achievement goal orientation. Specifically, perceived parent ego standards mediated the relationship between both ego and mastery coach climate scores and athletes' ego goal orientations, significantly reducing those relationships. Perceived parent mastery standards did not mediate the relationship between coach ego/mastery climate and youth ego achievement goal orientation.

\section{Discussion}

This study involved the development and application of a new measure of perceived parental success standards in sports. The PIMCQ-2 [38], though a commonly used measure for assessing parental motivational climate, was not utilized in this study for several reasons. As noted earlier, psychometric shortcomings and questions concerning the factorial validity and applicability of the PIMCQ-2 to our age group prompted the adaptation of the POSQ to assess perceived parental achievement standards, a core element of parent-initiated motivational climate. In contrast to the PIMCQ-2, the PPSSS displays orthogonality between the mastery and ego standards that mirrors the orthogonality shown between goal orientations in other studies $[39,40]$. The PPSSS adaptation was found to have strong factorial validity, exhibiting the desired two-factor orthogonal structure, and it exhibited a stronger CFA factor structure than the PIMCSQ2. Moreover, correlations between the corresponding PPSSS and coach climate measures revealed only 9 percent common variance in the parent and coach mastery scales and 13 percent in the ego scales, indicating that the children were discriminating between parent and coach orientations. From practical and theoretical perspectives, the orthogonality of the factors allows the PPSSS to be more easily used in the study of different combinations of perceived parental ego and mastery standards. Given these considerations, the PPSSS may be a useful tool for other researchers who are interested in athlete-perceived parental success standards within the sport domain and future research on the measure is needed. We should reiterate, however, that the parental success standards measured by the PPSSS are a central component of the parent-initiated motivational climate construct but are not coextensive with the additional facets measured by the PIMCQ-2. It is therefore likely that the additional facets of that measure, such as the creation of worry and 
an emphasis on succeeding with minimal effort, capture important variance that is related to other outcome measures. Clearly, additional empirical attention is warranted.

While the purpose of the study is the development of the PPSSS, establishing its construct validity, it requires that the measure predicts theoretically related variables (e.g., self-esteem) in a pattern of relationships consistent with theoretical expectations and previous empirical results. As predicted by Achievement Goal Theory and in accord with previous research (e.g., [4, 8, 12]), perceived mastery standards, whether communicated by parents or coaches, yielded theoretically consistent correlational results for all of the athlete outcome variables (i.e., lower anxiety, higher selfesteem, and a stronger mastery goal orientation), whereas ego standards were related to negative outcomes (higher anxiety and ego goal orientation scores and lower selfesteem). In no case was a theoretically inconsistent result observed in relation to performance anxiety, self-esteem, and achievement goal orientations. Overall, our results provide evidence that parental standards are meaningfully related to theoretically relevant outcomes, and they also support the construct validity of the PPSSS.

Coach-initiated motivational climate has exhibited strong and consistent relationships with the athlete outcome variables in this study. As an additional test of the potential influence of parental success standards, we wished to compare the strength of relationships between parental success standards and those exhibited by coach motivational climate. We therefore employed HLM analyses to assess the relative strength of relations between the coach and parental measures. A recent study [8] conducted in a highly structured national swimming program with high parental involvement revealed that the parental motivational climate was more influential than was the coach-initiated climate. O'Rourke et al. attributed their results to the pervasive and longerterm relationship parents have with their children. Our results, using a different measure of parental achievement standards, support a similar conclusion. In three of our four multilevel models, parent achievement success standards had the largest coefficient. These results are consistent with those in O'Rourke et al. [8]. The exception occurred in the case of anxiety, where coach-initiated mastery climate had a stronger protective effect than did parental standards. Somewhat surprisingly, coach ego climate was not significantly related to anxiety whereas parent ego standards were a significant positive predictor. Our directional results were consistent with previous findings regarding the impact of mastery and ego goal orientation and outcome measures. That is, mastery climates were found to predict decreased performance anxiety and increased self-esteem, whereas ego climates had the opposite effect. Also, parent mastery success standards and coach mastery climates predicted an increased likelihood of the athlete having a mastery achievement goal orientation and a decreased likelihood of having an ego orientation. Ego success standards and climates had the opposite effect.

In addition to the correlational and HLM results, the conclusion of relatively stronger parental standards was supported by a series of analyses involving PPSSS scores as potential mediators of coach climate relationships with the outcome variables. We found significant mediation by parental standards for some, but not all relations between coach climate and outcome scores. Specifically, parental mastery standards mediated the relation between coach mastery climate and the outcome variables of anxiety and mastery goal orientation. Parental ego standards mediated the relation between coach ego climate and both athlete anxiety and ego goal orientation. Parental ego standards also dampened the relationships between coach mastery climate and anxiety and ego goal orientation. These mediational results reinforce the conclusion that parental standards are of sufficient impact to influence the athlete's response to the motivational climates created by coaches.

The results of the O'Rourke et al. [8] study and the present study also have practical implications. As noted earlier, the Mastery Approach to Coaching motivational climate intervention for coaches $[16,31]$ has had salutary effects on coaching behaviors and on athletes' anxiety, selfesteem, and achievement goal orientations [16, 52, 53]. Given the evidence that parents' achievement standards are of equal or more influence, a motivational climate intervention for parents could have a strong positive impact on athletes' psychosocial development. As an example, Smoll et al. [31] conducted an intervention study designed to jointly influence coaches and parents in a youth sport program. Coaches received the Mastery Approach to Coaching intervention, and parents received a companion Mastery Approach to Parenting in Sports workshop. This group was compared with a no-intervention control condition. Athletes in the control condition whose parents and coaches did not receive the mastery climate interventions exhibited higher anxiety scores at the end of the season than they had at the beginning. In contrast, athletes whose parents and coaches received the Mastery Approach interventions exhibited decreased anxiety scores over the course of the season. This study suggests that the feasibility of this kind of dual training model (i.e., trainings for parents and coaches) is promising. However, because the effects of the parent and coach interventions were necessarily confounded in this study, their relative contributions to the positive results are unknown. More conclusive results would be yielded by a study with a factorial design that could measure the relative impact of a coach-only mastery intervention, a parent-only mastery intervention, a coach and parent mastery intervention, and a control condition. This design would allow for a comparison of main and interactive effects of the motivational climate interventions on young athlete outcomes.

4.1. Limitations and Future Directions. Several limitations of this study should be noted. The data in this study are correlational in nature, and as in all such studies causality cannot be inferred on the basis of the statistical relationship. We should also note that this study only included male coaches, as (surprisingly) no female coaches were involved in the programs. Therefore, generalizations cannot be made regarding the potential impact of female coaches on athlete outcomes. Second, because over $90 \%$ of the athletes reported playing other sports, it is possible that the influence of coaches in other sports may be diluting the influence of the basketball 
coaches we studied. Additionally, we chose to use the wellvalidated MCSYS so as to compare the predictive power of the PPSSS with an established coach climate measure that also exhibits a clear two-factor structure. We are encouraged by the relatively modest correlations between the corresponding mastery and ego scales of both the PPSSS and MCSYS, suggesting that the athletes were making a clear distinction between coach and parental standards of success. That said, however, we suggest that a corresponding coach version of the PPSSS be developed and evaluated. If such a measure should exhibit the degree of orthogonality that the PPSSS scales exhibit, as well as its other psychometric strengths, it could be a useful tool in future research. Further, if it were established that athletes could distinguish between the achievement standards expressed by parents and coaches, the use of corresponding instruments would permit an even more definitive examination of coach and parent influences. A final refinement might involve an 18-item forced-choice format in which each mastery item was paired with each of the ego items and athletes were asked to select the alternative that is most important to the parent. This format might create more separation between mastery and ego scores. Finally, while we now have a better understanding of the relative impact of parents and coaches on young athletes in highly competitive as well as recreational settings, further research is warranted on areas, such as coach gender and the potentially differential impact of mothers and fathers.

\section{Appendix}

The Perceived Parent Success Standards Scale (PPSSS) is as follows.

\section{What My Parents Think Success Is in Sports}

We want to know what your PARENTS think about what it means to be successful. Show us how much you agree with each sentence by circling your choice. There are no right or wrong answers.

When I play sports, it is most important TO MY PARENTS that...

(1) I beat other people.

$\begin{array}{cccc}1 & 2 & 3 & 4 \\ \text { Strongly } & \text { Disagree } & \text { Agree } & \begin{array}{c}\text { Strongly } \\ \text { Agree }\end{array}\end{array}$

(2) I am clearly better than others.

$\begin{array}{cccc}1 & 2 & 3 & 4 \\ \text { Strongly } & \text { Disagree } & \text { Agree } & \begin{array}{c}\text { Strongly } \\ \text { Agree }\end{array}\end{array}$

(3) I am the best.

$\begin{array}{cccc}1 & 2 & 3 & 4 \\ \text { Strongly } & \text { Disagree } & \text { Agree } & \begin{array}{c}\text { Strongly } \\ \text { Agree }\end{array}\end{array}$

(4) I work hard.

$\begin{array}{cccc}1 & 2 & 3 & 4 \\ \text { Strongly } & \text { Disagree } & \text { Agree } & \begin{array}{c}\text { Strongly } \\ \text { Agree }\end{array}\end{array}$

(5) I show clear personal improvements.

$\begin{array}{cccc}1 & 2 & 3 & 4 \\ \text { Strongly } & \text { Disagree } & \text { Agree } & \begin{array}{c}\text { Strongly } \\ \text { Agree }\end{array}\end{array}$

(6) I play better than my opponents.

$\begin{array}{cccc}1 & 2 & 3 & 4 \\ \text { Strongly } & \text { Disagree } & \text { Agree } & \begin{array}{c}\text { Strongly } \\ \text { Agree }\end{array}\end{array}$

(7) I accomplish something others cannot do.

$\begin{array}{cccc}1 & 2 & 3 & 4 \\ \text { Strongly } & \text { Disagree } & \text { Agree } & \begin{array}{c}\text { Strongly } \\ \text { Agree }\end{array}\end{array}$

(8) I reach a goal.

$\begin{array}{cccc}1 & 2 & 3 & 4 \\ \text { Strongly } & \text { Disagree } & \text { Agree } & \begin{array}{c}\text { Strongly } \\ \text { Agree }\end{array}\end{array}$

(9) I overcome difficulties.

$\begin{array}{cccc}1 & 2 & 3 & 4 \\ \text { Strongly } & \text { Disagree } & \text { Agree } & \begin{array}{c}\text { Strongly } \\ \text { Agree }\end{array}\end{array}$

(10) I master something I couldn't do before.

$\begin{array}{cccc}1 & 2 & 3 & 4 \\ \text { Strongly } & \text { Disagree } & \text { Agree } & \begin{array}{c}\text { Strongly } \\ \text { Agree }\end{array}\end{array}$

(11) I show other people I am the best.

\begin{tabular}{|c|c|c|c|}
\hline 1 & 2 & 3 & 4 \\
\hline $\begin{array}{l}\text { Strongly } \\
\text { Disagree }\end{array}$ & Disagree & Agree & $\begin{array}{l}\text { Strongly } \\
\text { Agree }\end{array}$ \\
\hline
\end{tabular}

(12) I perform to the best of my ability.

$\begin{array}{cccc}1 & 2 & 3 & 4 \\ \text { Strongly } & \text { Disagree } & \text { Agree } & \begin{array}{c}\text { Strongly } \\ \text { Agree }\end{array}\end{array}$

Key: mastery standards: items (4), (5), (8), (9), (10), (12); ego standards: items (1), (2), (3), (6), (7), (11).

\section{Conflict of Interests}

The authors declare that there is no conflict of interests regarding the publication of this paper.

\section{References}

[1] Sports and Fitness Industry Association, 2015 U.S. Trends in Team Sports: The Ultimate Report on the State of Team Sports, Sports and Fitness Industry Association, 2015. 
[2] US Census Bureau and Population Division, Annual Estimates of the Resident Population for Selected Age Groups by Sex for the United States, States, Counties, and Puerto Rico Commonwealth and Municipios: April 1, 2010 to July 1, 2014, US Census Bureau, Suitland, Md, USA, 2015.

[3] J. G. Nicholls, "Achievement motivation: conceptions of ability, subjective experience, task choice, and performance," Psychological Review, vol. 91, no. 3, pp. 328-346, 1984.

[4] S. McArdle and J. K. Duda, "Implications of the motivational climate in youth sports," in Children and Youth in Sport: A Biopsychosocial Perspective, F. L. Smoll and R. E. Smith, Eds., pp. 409-434, Kendall/Hunt, Dubuque, Iowa, USA, 2nd edition, 2002.

[5] M. Reinboth and J. L. Duda, "Perceived motivational climate, need satisfaction and indices of well-being in team sports: a longitudinal perspective," Psychology of Sport and Exercise, vol. 7, no. 3, pp. 269-286, 2006.

[6] S. A. White, "Parent-created motivational climate," in Social Psychology in Sport, S. Jowett and D. Lavallee, Eds., vol. 10, pp. 131-143, Human Kinetics, Champaign, Ill, USA, 2007.

[7] R. E. Smith, F. L. Smoll, and S. P. Cumming, "Motivational climate and changes in young athletes' achievement goal orientations," Motivation and Emotion, vol. 33, no. 2, pp. 173-183, 2009.

[8] D. J. O'Rourke, R. E. Smith, F. L. Smoll, and S. P. Cumming, "Relations of parent- and coach-initiated motivational climates to young athletes' self-esteem, performance anxiety, and autonomous motivation: who is more influential?" Journal of Applied Sport Psychology, vol. 26, no. 4, pp. 395-408, 2014.

[9] J. L. Duda and D. Treasure, "Motivational processes and the facilitation of quality engagement in sport," in Applied Sport Psychology, J. M. Williams, Ed., Mayfield, Mountain View, Calif, USA, 2009.

[10] C. Ames, "Classrooms: goals, structures, and student motivation," Journal of Educational Psychology, vol. 84, no. 3, pp. 261271, 1992.

[11] J. L. Duda, "Motivational processes and the facilitation of quality engagement in sport," in Handbook of Competence and Motivation, A. J. Elliot and C. S. Dweck, Eds., pp. 318-335, Guilford, New York, NY, USA, 2005.

[12] G. C. Roberts, D. C. Treasure, and D. E. Conroy, "Understanding the dynamics of motivation in sport and physical activity," in Handbook of Sport Psychology, G. Tenenbaum and R. C. Eklund, Eds., pp. 3-30, John Wiley \& Sons, Hoboken, NJ, USA, 3rd edition, 2007.

[13] J. L. Duda, A. E. Smart, and M. K. Tappe, "Predictors of adherence in the rehabilitation of athletic injuries: an application of personal investment theory," Journal of Sport \& Exercise Psychology, vol. 11, no. 4, pp. 367-381, 1989.

[14] M. Kavussanu and G. C. Roberts, "Motivation in physical activity contexts: the relationship of perceived motivational climate to intrinsic motivation and self-efficacy," Journal of Sport \& Exercise Psychology, vol. 18, no. 3, pp. 264-280, 1996.

[15] R. E. Smith, S. P. Cumming, and F. L. Smoll, "Development and validation of the motivational climate scale for youth sports," Journal of Applied Sport Psychology, vol. 20, no. 1, pp. 116-136, 2008.

[16] R. E. Smith, F. L. Smoll, and S. P. Cumming, "Effects of a motivational climate intervention for coaches on young athletes' sport performance anxiety," Journal of Sport and Exercise Psychology, vol. 29, no. 1, pp. 39-59, 2007.
[17] T. S. Horn and J. L. Horn, "Family influences on children's sport and physical activity participation, behavior, and psychosocial responses," in Handbook of Sports Psychology, G. G. Tenenbaum and R. C. Eklund, Eds., pp. 685-711, John Wiley \& Sons, Hoboken, NJ, USA, 3rd edition, 2007.

[18] J. L. Duda, "The conceptual and empirical foundations of Empowering Coaching ${ }^{\mathrm{TN}}$ : setting the stage for the PAPA project," International Journal of Sport and Exercise Psychology, vol. 11, no. 4, pp. 311-318, 2013.

[19] N. Ntoumanis, I. M. Taylor, and C. Thøgersen-Ntoumani, "A longitudinal examination of coach and peer motivational climates in youth sport: implications for moral attitudes, wellbeing, and behavioral investment," Developmental Psychology, vol. 48, no. 1, pp. 213-223, 2012.

[20] N. Ntoumanis and S. J. H. Biddle, "A review of motivational climate in physical activity," Journal of Sports Sciences, vol. 17, no. 8, pp. 643-665, 1999.

[21] R. Lewthwaite and T. K. Scanlan, "Predictors of competitive trait anxiety in male youth sport participants," Medicine and Science in Sports and Exercise, vol. 21, no. 2, pp. 221-229, 1989.

[22] D. J. O'Rourke, R. E. Smith, F. L. Smoll, and S. P. Cumming, "Trait anxiety in young athletes as a function of parental pressure and motivational climate: is parental pressure always harmful?" Journal of Applied Sport Psychology, vol. 23, no. 4, pp. 398-412, 2011.

[23] R. E. Smith, F. L. Smoll, S. P. Cumming, and J. R. Grossbard, "Measurement of multidimensional sport performance anxiety in children and adults: the sport anxiety scale-2," Journal of Sport and Exercise Psychology, vol. 28, no. 4, pp. 479-501, 2006.

[24] T. K. Scanlan and M. W. Passer, "Factors related to competitive stress among male youth sport participants," Medicine \& Science in Sports \& Exercise, vol. 10, no. 2, pp. 103-108, 1978.

[25] T. K. Scanlan and M. W. Passer, "Sources of competitive stress in young female athletes," Journal of Sport Psychology, vol. 1, no. 2, pp. 151-159, 1979.

[26] T. K. Scanlan and M. W. Passer, "Determinants of competitive performance expectancies of young male athletes," Journal of Personality, vol. 49, no. 1, pp. 60-74, 1981.

[27] J. Liukkonen, V. Barkoukis, A. Watt, and T. Jaakkola, "Motivational climate and students' emotional experiences and effort in physical education," The Journal of Educational Research, vol. 103, no. 5, pp. 295-308, 2010.

[28] R. E. Smith, "A component analysis of athletic stress," in Sport for Children and Youths, M. R. Weiss and D. Gould, Eds., pp. 107-111, Human Kinetics, Champaign, Ill, USA, 1986.

[29] E. M. Pomerantz and R. A. Thompson, "Parents' role in children's personality development: the psychological resource principle," in Handbook of Personality: Theory and Research, $\mathrm{O}$. P. John, R. W. Robins, and L. A. Pervin, Eds., vol. 3, pp. 351-374, Guilford, New York, NY, USA, 2008.

[30] D. J. O'Rourke, R. E. Smith, F. L. Smoll, and S. P. Cumming, "Parent-initiated motivational climate, self-esteem, and autonomous motivation in young athletes: testing propositions from achievement goal and self-determination theories," Child Development Research, vol. 2012, Article ID 393914, 9 pages, 2012.

[31] F. L. Smoll, R. E. Smith, and S. P. Cumming, "Effects of coach and parent training on performance anxiety in young athletes: a systemic approach," Journal of Youth Development, vol. 2, Article ID 0701FA002, 2007.

[32] F. L. Smoll, R. E. Smith, N. P. Barnett, and J. J. Everett, "Enhancement of children's self-esteem through social support 
training for youth sport coaches," Journal of Applied Psychology, vol. 78, no. 4, pp. 602-610, 1993.

[33] R. E. Smith and F. L. Smoll, "Self-esteem and children's reactions to youth sport coaching behaviors: a field study of selfenhancement processes," Developmental Psychology, vol. 26, no. 6, pp. 987-993, 1990.

[34] E. Kocayörük, E. Altıntas, and M. A. İçbay, “The perceived parental support, autonomous-self and well-being of adolescents: a cluster-analysis approach," Journal of Child and Family Studies, vol. 24, no. 6, pp. 1819-1828, 2015.

[35] E. T. Randall, A. M. Bohnert, and L. V. Travers, "Understanding affluent adolescent adjustment: the interplay of parental perfectionism, perceived parental pressure, and organized activity involvement," Journal of Adolescence, vol. 41, pp. 56-66, 2015.

[36] D. R. Sawitri and P. A. Creed, "Perceived career congruence between adolescents and their parents as a moderator between goal orientation and career aspirations," Personality and Individual Differences, vol. 81, pp. 29-34, 2015.

[37] J. Stoeber and U. Eismann, "Perfectionism in young musicians: relations with motivation, effort, achievement, and distress," Personality and Individual Differences, vol. 43 , no. 8, pp. 21822192, 2007.

[38] S. A. White, "Adolescent goal profiles, perceptions of the parentinitiated motivational climate, and competitive trait anxiety," The Sport Psychologist, vol. 12, no. 1, pp. 16-28, 1998.

[39] G. C. Roberts, D. C. Treasure, and G. Balague, "Achievement goals in sport: the development and validation of the Perception of Success Questionnaire," Journal of Sports Sciences, vol. 16, no. 4, pp. 337-347, 1998.

[40] S. P. Cumming, R. E. Smith, F. L. Smoll, M. Standage, and J. R. Grossbard, "Development and validation of the Achievement Goal Scale for Youth Sports," Psychology of Sport and Exercise, vol. 9, no. 5, pp. 686-703, 2008.

[41] S. M. Colby, T. A. O'Leary, and P. M. Monti, Eds., Adolescents, Alcohol, and Substance Abuse: Reaching Teens through Brief Interventions, Guilford Press, New York, NY, USA, 2001.

[42] S. A. White, J. L. Duda, and S. Hart, "An exploratory examination of the parent-initiated motivational climate questionnaire," Perceptual and Motor Skills, vol. 75, no. 3, pp. 875-880, 1992.

[43] A. Ortega, Á. Sicilia, and D. González-Cutre, "Validación preliminar del cuestionario del clima motivacional iniciado por los padres-2 (PIMCQ-2)," Revista Latinoamericana de Psicología, vol. 45, no. 1, pp. 35-45, 2013.

[44] D. J. Bauer, K. J. Preacher, and K. M. Gil, "Conceptualizing and testing random indirect effects and moderated mediation in multilevel models: new procedures and recommendations," Psychological Methods, vol. 11, no. 2, pp. 142-163, 2006.

[45] R. C. Wylie, The Self-Concept, University of Nebraska Press, Lincoln, Neb, USA, 1979.

[46] Y. Rosseel, "Lavaan: an R package for structural equation modeling," Journal of Statistical Software, vol. 48, no. 2, pp. 136, 2012.

[47] K. A. Bollen, Structural Equations with Latent Variables, John Wiley \& Sons, New York, NY, USA, 1989.

[48] X. Fan, B. Thompson, and L. Wang, "Effects of sample size, estimation methods, and model specification on structural equation modeling fit indexes," Structural Equation Modeling, vol. 6, no. 1, pp. 56-83, 1999.

[49] J. C. Nunnally and I. Bernstein, Psychometric Theory, McGrawHill, New York, NY, USA, 3rd edition, 1994.
[50] T. A. B. Snijders and R. J. Bosker, Multilevel Analysis: An Introduction to Basic and Advanced Multilevel Modeling, Sage, Los Angeles, Calif, USA, 2nd edition, 2012.

[51] Z. Zhang, M. J. Zyphur, and K. J. Preacher, “Testing multilevel mediation using hierarchical linear models: problems and solutions," Organizational Research Methods, vol. 12, no. 4, pp. 695-719, 2009.

[52] F. L. Smoll, R. E. Smith, and S. P. Cumming, "Effects of a motivational climate intervention for coaches on changes in young athletes' achievement goal orientations," Journal of Clinical Sport Psychology, vol. 1, no. 1, pp. 23-46, 2007.

[53] F. L. Smoll and R. E. Smith, "Educating youth sport coaches: an evidence-based training program," in Coach Education Essentials, M. Thompson and K. Dieffenbach, Eds., Human Kinetics, Champaign, Ill, USA. 


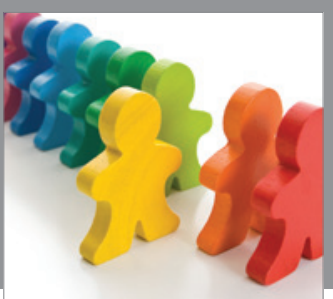

Autism

Research and Treatment
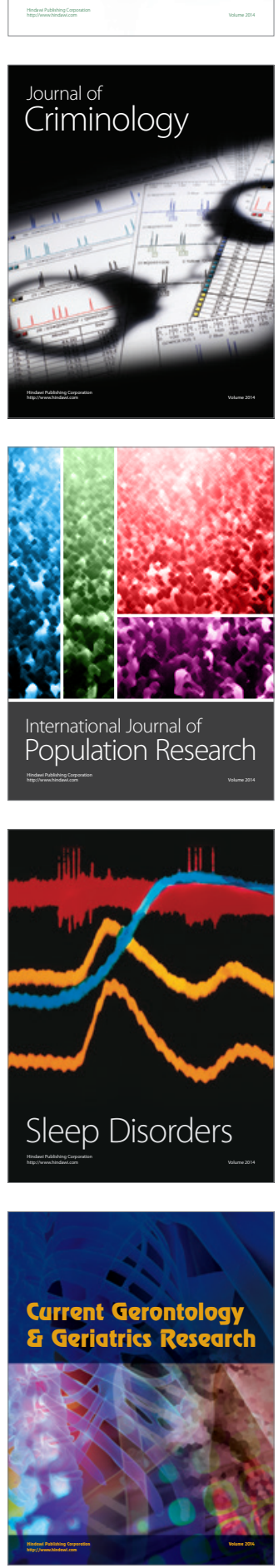

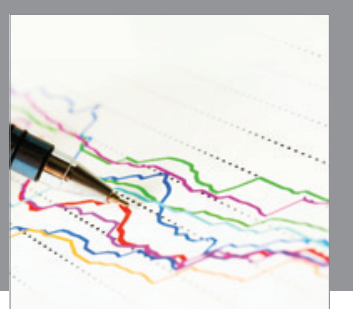

Economics

Research International
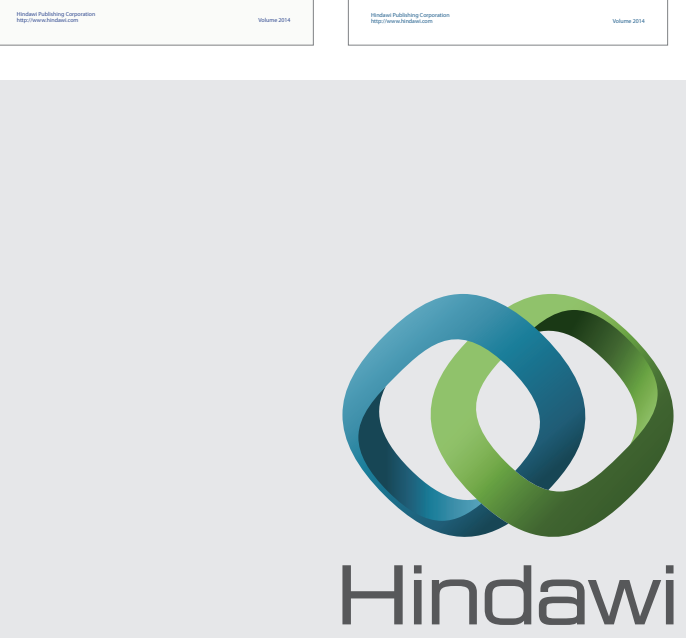

Submit your manuscripts at

http://www.hindawi.com
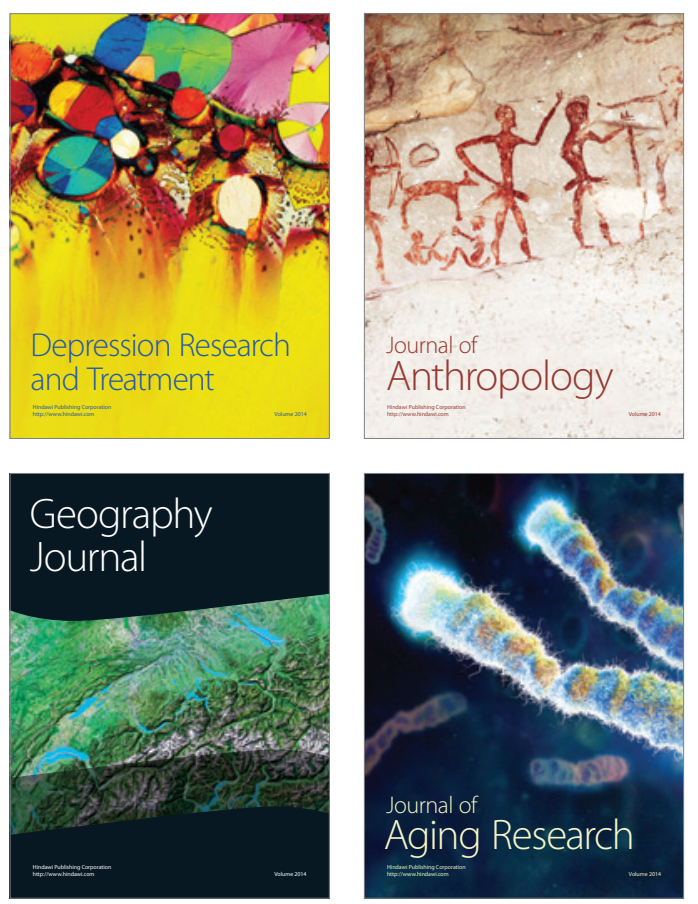
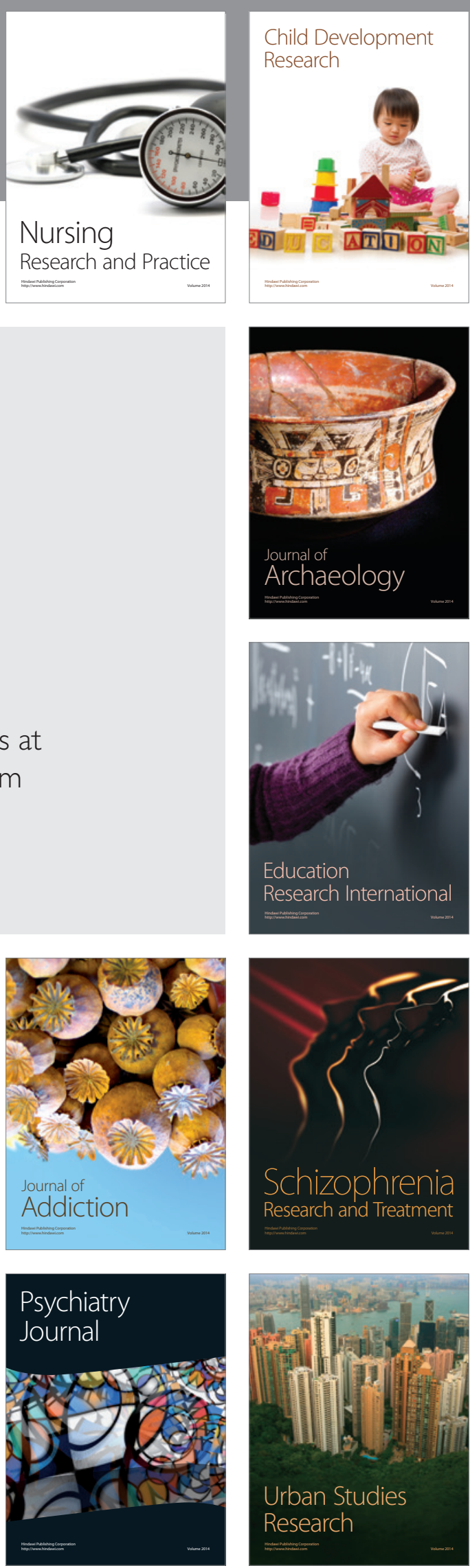